\title{
Practical Validation of Economic Efficiency Modelling Method for Multi-Boiler Heating System
}

\author{
Aleksejs Jurenoks ${ }^{1 *}$, Svetlana Jurenoka ${ }^{1}$, Leonids Novickis ${ }^{1}$
}

${ }^{1}$ Riga Technical University, LATVIA

*Corresponding Author: aleksejs.jurenoks@rtu.lv

Citation: Jurenoks, A., Jurenoka, S. and Novickis, L. (2017). Practical Validation of Economic Efficiency Modelling Method for Multi-Boiler Heating System. Journal of Information Systems Engineering \& Management, 2(4), 26. https://doi.org/10.20897/jisem.201726

Published: December 22, 2017

\begin{abstract}
In up-to-date conditions information technology is frequently associated with the modelling process, using computer technology as well as information networks. Statistical modelling is one of the most widespread methods of research of economic systems. The selection of methods of modelling of the economic systems depends on a great number of conditions of the researched system. Modelling is frequently associated with the factor of uncertainty (or risk), who's description goes outside the confines of the traditional statistical modelling, which, in its turn, complicates the modelling which, in its turn, complicates the modelling process. This article describes the modelling process of assessing the economic efficiency of a multi-boiler adaptive heating system in real-time systems which allows for dynamic change in the operation scenarios of system service installations while enhancing the economic efficiency of the system in consideration.
\end{abstract}

Keywords: adaptive system, model, simulation modelling, optimization

\section{INTRODUCTION}

Nowadays, using modern technologies means having the possibility of integrating widely used analytical research methods in data processing systems in real time, which will enable the change of certain scenarios of the model relatively easily in order to monitor their effects on the operators of the system. The analytical models relating the modelling process described in the scientific literature (Хэмди and Таха, 2001; Экономико, 1999) are too complex and require large computer resources for their execution; as a result, in the adaptive data processing systems their task is assigned to the system coordinator module.

These days the heating systems which use several low-power boilers are more popular than using only a single boiler (Broomhead et al., 2017). This article describes a heating system that is used in one particular private home sector in Latvia. The total heating system has a capacity of $360 \mathrm{~kW}$. The power is supplied by 6 boilers with a nominal power of $60 \mathrm{~kW}$ each. The heating system provides 10 private houses and a shopping center with heating and hot water.

The article describes a real-time method of modelling the heating system by using the developed method for adjusting the capacity of boilers by selecting a boiler room operating scenario.

\section{RELATED WORKS}

Today, the main studies which are related to the introduction of Smart environment into people's daily lives are associated with the device, network, software security and user interface development, that will allow the 
automation of the management processes and the reduction of the energy consumption in systems. Nowadays the discovery of energy consumption is ongoing and most of the producers unfortunately do not define it as main priority (Jurenoks and Jokić, 2017). The competitiveness of European technologies could strengthen the European position in the global market for energy effective solutions. The EU is making rapid progress towards establishing Europe-wide energy consumption standards; however, most European countries have established and follow their own set of regulations (Badea and Andrei, 2016).

In the recent years, the trend in urbanization has increased in Latvia and over $68 \%$ of Latvia's population live in the suburbs. By using urban legislation citizens are prohibited or it is made impossible to use private local heating systems instead of central systems. Any person living in an apartment is attached to the heat resources supplied centrally. Since 2011, the inhabitants can choose the suppliers of heat resources or secure the access to their own central boiler house that uses renewable or alternative energy sources.

The result is that the provision of common power and work algorithms for boiler houses or heating systems is necessary in order to ensure the efficient management of the economic system. A wide range of general formulae are present today (Li et al., 2016) allowing the necessary heating system capacity to be defined for a heating area, but in real practice the boiler capacity and the usage algorithm are affected by a number of factors (set room temperature, outdoor temperature, operating schedule, heat loss etc.) and as a result the "properly constructed heating system" may prove to be inefficient.

\section{POSITION OF THE MODELLING TASK}

Modelling is commonly used to model real events or processes, resulting in the attribution of the term simulation modelling to certain dynamic models which include information about a complex probability system within a defined time frame (Lapin, 1993). This article explores the modelling of discrete events when used in situations where separate elements are considered, the probability allocation of which has been interrupted (for example, a model followed by an outdoor air temperature fluctuation in any period of time). The model may be constructed as a normal determined model or, if there is any uncertainty, as a continuous simulation model. The modelling of discrete events is generally used when determining the impact of each event on the model (Jansons and Jurēnoks, 2005). Another example may be a linear programming model or a decision analysis model (Jansons and Jurēnoks, 2006). Such models allow for the planning of the operational processing priority and the quantity of technical resources required, during a given period of time. However, it is quite difficult to include detailed decisions in such models which would impact the process of system data processing. Such decisions may include the planning of processes to be implemented, the withholding and release of necessary resources, the records of pre-processed and processed information as well as the decisions relating to system inspection, improvement and change of the operational method (Jurenoks and Jansons, 2008). The simulation model of discreet events can be used in complex problems (with many interrelated values) for investigating advanced details. In most cases the discrete event simulation modelling is used to model real systems which consist of conflicting processes that activate simultaneously and can demand the missing resources at the same time. An example of such processes might be the modelling of launched process information row modelling involving the tasks expected to be serviced (e.g. the flow of input information or the processes to be conducted within linear systems). The created simulation model is much more convenient and safer in terms of research than the modelling of a real situation, in addition, the scenarios within the model can be changed relatively easily in order to monitor their effects on the operators of the system.

When describing the modelling methodology, it is assumed that there is a simple service system alongside refusals and three servicing devices, such as the heating system with three boilers of equal power which ensure the heating for 6 identical houses (Figure 1). On a daily basis, the heating system receives a flow of requests from the

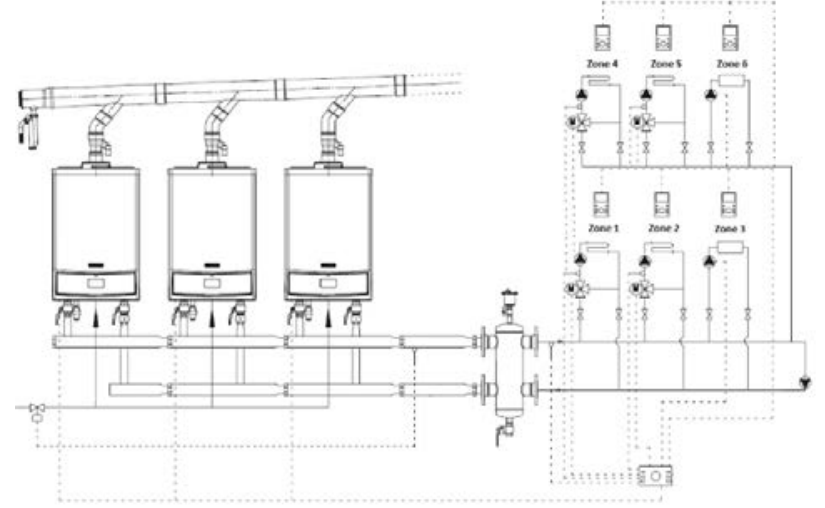

Figure 1. Multi-boiler heating system concept structure 
Table 1. Model service systems' output data

\begin{tabular}{cccccccccccc}
\hline & $\mathbf{1}$ & $\mathbf{2}$ & $\mathbf{3}$ & $\mathbf{4}$ & $\mathbf{5}$ & $\mathbf{6}$ & $\mathbf{7}$ & $\mathbf{8}$ & $\mathbf{9}$ & $\mathbf{1 0}$ \\
\hline$\lambda$ & 1.2 & 1.4 & 1.3 & 1.5 & 1.7 & 2.0 & 2.6 & 2.9 & 3.0 & 1.7 \\
\hline$s$ & 4.0 & 3.0 & 2.0 & 5.0 & 3.0 & 3.0 & 4.0 & 4.0 & 5.0 & 2.0 \\
\hline$t_{\text {apk }}$ & 0.8 & 0.7 & 0.5 & 0.6 & 0.4 & 0.5 & 0.7 & 0.6 & 0.6 & 0.4 \\
\hline$C_{m}$ & 5.0 & 6.0 & 7.0 & 8.0 & 9.0 & 8.0 & 5.0 & 7.0 & 6.0 & 10.0 \\
\hline$C_{a p k}$ & 2.0 & 3.0 & 2.5 & 2.4 & 2.6 & 3.2 & 3.4 & 3.0 & 2.2 & 2.8 \\
\hline$C_{e k s p}$ & 1 & 1.5 & 2 & 1.5 & 1.8 & 2.0 & 1.7 & 1.5 & 1.1 & 1.4 \\
\hline$C_{d}$ & 0.2 & 0.25 & 0.3 & 0.25 & 0.35 & 0.42 & 0.35 & 0.26 & 0.36 & 0.45 \\
\hline
\end{tabular}
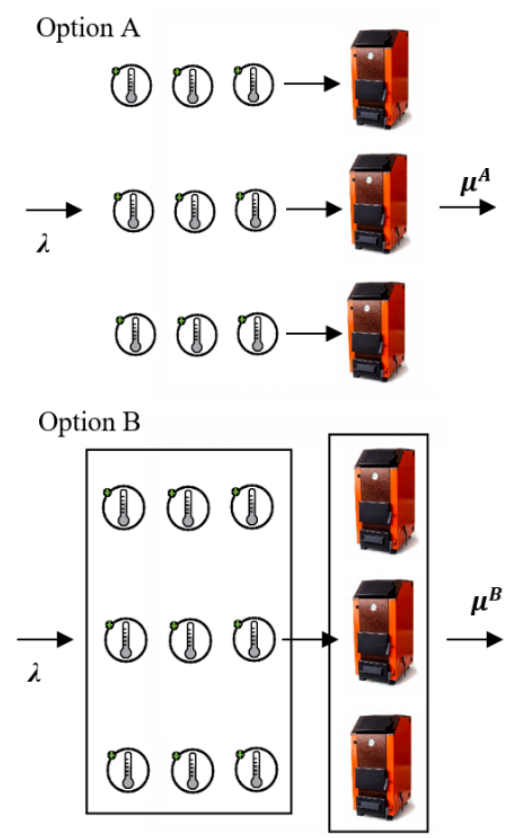

Figure 2. The functional schemes for a modelled service system for variants A and B

sensor nodes (there is a need to raise the water temperature of the heating system by 1 unit) with the intensity of $\lambda$. The average time to process a single request is $t_{a p k}$.

The values for variant $A$ of the modelled service system parameters are shown in Table 1 where:

$\lambda$ - the intensity of the incoming requests within the modelling system;

$s$ - number of servicing devices in the modelling system;

$t_{a p k}$ - the time required to raise the water temperature by 1 degree;

$C_{m}$ - servicing costs of a single demand;

$C_{a p k}$ - additional amount of resource power spent for servicing a single request which includes energy costs and the wear of the device;

$C_{e k s p}$ - the amount of the energy used for servicing a single device per one unit of time;

$C_{d}$ - the power used associated with the idle-state of a single servicing device per one unit of time.

The functional graphical representation of the modelled servicing system for variants A and B is shown in Figure 2.

As a result, the system module has the purpose of modelling in order to determine whether or not it is convenient to organise the operation of the modelling system in a way that all the servicing devices would service incoming requests immediately which will reduce the total servicing time in the system (option B).

\section{The Technical Parameters Characterising the Modelling Service System}

The technical parameters of a functioning modelling system are as follows:

$\lambda$ - the intensity of incoming requests in a modelling system;

$\mu$ - the intensity of the servicing requests in a modelling system;

$v$ - the intensity of the requests not being deployed from the queue;

$s-$ the number of servicing devices in the modelling system;

$\lambda_{e f}$ - the effective throughput of the modelling system. 
The effective throughput of the modelling system is the average number of requests that have arrived in the modelling system which might be serviced within the system in one unit of time;

$m$ - the maximum row length in the modelling system;

$\rho$ - the reduced intensity of the flow of requests (the average number of requests entering the system for the average time of servicing);

$\rho^{*}$ - the flow rate of requests (the average number of incoming requests per one servicing device in the system per average servicing time of one request);

$\rho_{v}$ - the reduced intensity rate of the flow of unsolicited requests (the average number of unsolicited requests leaving the system per average service time of one request);

$q$ - the relative throughput of the modelling system.

The relative throughput of the modelling system is the ratio of the average number of serviced requests per one unit of time to the average number of the incoming requests for servicing during the same time;

$P_{0}$ - the probability that the random request of the servicing system will reach the system only when all servicing devices are free (the probability of the fact that a servicing device is free);

$P_{k}$ - the probability that precisely servicing devices $\mathrm{k}$ are operating in the servicing system;

$P_{a t t}$ - the probability that the random request of the servicing system will reach the system only when all servicing devices are occupied (the servicing system with refusals referring to the refusal probability);

$P_{\text {gaid }}$ - the probability of waiting in the servicing system in relation to waiting;

$P_{\text {att+neapm }}$ - the probability that the random request of the servicing system will leave the system unsolicited (the request might leave the system due to the limited length of its row or if the expected waiting time in the queue exceeds its expected waiting time limit - "neutral request");

$W_{\text {sist }}$ - the average time of incoming requests within the servicing system (in the service as well as in the queue);

$W_{q}$ - the average request waiting time in the service queue;

$L_{\text {sist }}$ - the average number of requests in the servicing system;

$L_{q}$ - the average queue length of servicing requests;

$L_{\text {apk }}$ - the average number of requests to service in the service system;

$L_{\text {briv }}$ - the average number of servicing devices not operating in the servicing system;

$K_{t g}$ - the idle-time factor in the servicing systems;

$K_{S l}$ - the service system usage (load) factor (all servicing device usage factor in the servicing system).

\section{Economic Indicators Characterising the Modelling Service Systems}

The economic efficiency of operating the technical economic system may be expressed in certain service system performance parameters, such as resource preserving, which can be obtained through one of the variations of heating system operation (variant A or variant B). Hence, the optimisation of the service system should take the form of minimizing expenses from the results of its operations. Nonetheless, part of the requests in the modelling service systems with refusals leave the system unsolicited which results in a servicing system that is a technically economic system and does not meet the certain request leading to causing discomfort to the consumers. In addition, the consumer will increase the costs of using alternative spin-off energy (electricity), whose size should also be assessed. The optimisation of the operation of the assisted servicing system shall be directly related to an increase in the capacity of the service system, by a reduction in the queue, which influences the loss of potential customers without obtaining the necessary amount of heat energy. This optimization can result in an increase in the number of servicing devices in the modelling service system. On the other hand, the question arises - what is the limit of the number of servicing devices in the modelling system? As far as it is known, an overly large number of servicing devices in the system may lead to outages, so that not only the expenditure relating to the maintenance of unused equipment in the enterprise may be increased, but it will also result in losses from their downtime. In order to answer the questions raised and to improve the effectiveness of the running system, the secondary modelling module, in real time, shall carry out the service system study when defining the main economic characteristics of its operation.

The economic parameters of the operation of a servicing system are as follows:

$C_{m}$ - servicing costs of a single demand;

$C_{a p k}$ - additional amount of resource power spent for servicing a single request which includes energy costs and the wear of the device;

$C_{\text {gaid }}$ - the costs associated with the waiting for one order (heating costs using alternative heating energy resources or the costs which are required for levelling higher temperature fluctuations);

$C_{e k s p}$ - the operating costs of one service device per one unit of time;

$C_{d}$ - the power used associated with the idle-state of a single servicing device per one unit of time; 
$I_{t}$ - the income generated by the servicing system during the period of operation. The income has been determined dynamically based on the amount of energy produced;

$P_{t}-$ the profit from servicing system activities in the time frame $t$;

$P_{\text {nesanem }, t}^{\text {att }}$ - the lost income or "missed" income during the time frame $\mathrm{t}$ associated with the request waiting time results are achieved through the use of alternative heating methods.

The income from the servicing system operating time during the time frame $t$ is determined by using the formula:

$$
I_{t}=C_{m} \cdot \lambda_{e f} \cdot t
$$

where $\lambda_{e f}$ is the effective throughput of the servicing system (the average service number of requests for time frame $t$ ).

The effective throughput of the service system is calculated according to the formula:

$$
\lambda_{e f}=\lambda\left(1-p_{a t t}\right)
$$

In determining the rational organisation of the operation of the servicing system, the expenditure function $C_{z}$ can be formed in relation to the service system operation. The function to be operated is created taking account of all the expenses related to the operation of the servicing system, the functioning of the system as well as the mode of service and the number of servicing devices. The function $C_{z}$ related to the operation of the servicing system for the time frame $t$ is expressed as follows:

$$
C_{z(s), t}^{a p k}=\left(C_{d} \cdot L_{\text {briv }}+C_{e k s p} \cdot L_{a p k}+C_{a p k} \cdot \lambda_{e f}+C_{\text {gaid }} \cdot L_{q}\right) t
$$

where $t$ is the operation time of the servicing system (modelling time without taking into account the transition process);

$\lambda$ - the rate of incoming requests per time unit;

$L_{\text {apk }}$ - the average number of requests to service;

$L_{\text {briv }}$ - the average number of available servicing devices;

$\lambda_{e f}$ - effective throughput of the system in one time unit.

For the service system in which the withdrawal period $(t)$ is to be used in function Cattz(s), $t$ may be expressed as follows:

$$
C_{z(s), t}^{a t t}=\left(C_{d} \cdot L_{b r i v}+C_{e k s p} \cdot L_{a p k}+C_{a p k} \cdot \lambda_{e f}\right) t
$$

In this case, it should be taken into account that the service system with refusals can be accompanied by the flow of requests. Their departure from the system leads to "lost income" $P_{\text {nesan, }}^{\text {att }}$, which is estimated to be based on the formula:

$$
P_{\text {nesan }, t}^{a t t}=P_{0}^{a t t} \cdot\left(\lambda-\lambda_{\text {ef }}\right) \cdot t
$$

where $P_{0}^{a t t}$ is the lost income or "missed" service system income related to one request leaving the system.

Value $P_{0}^{a t t}$ is calculated by means of the formula:

$$
P_{0}^{a t t}=C_{m}-C_{a p k}-\frac{C_{d} \cdot L_{\text {briv }}+C_{e k s p} \cdot L_{a p k}+C_{g a i d} \cdot L_{q}}{\lambda_{e f}}
$$

The average number of service requests in service systems AS $\left(L_{a p k}\right)$ is calculated using the formula:

$$
L_{\text {apk }}=s-L_{\text {briv }}
$$

where $S$ is the number of existing service devices.

The income received from servicing systems during the time frame $t$ is generally calculated according to the formula:

$$
P_{t}=I_{t}-C_{z(s), t}^{a t t}=C_{m} \cdot \lambda_{e f} \cdot t-C_{z(s), t}^{a t t}
$$

When using formula (8), an optimization request for work with a service system can be set:

$$
P_{t}=I_{t}-C_{z(s), t}^{a t t} \rightarrow \max
$$

In servicing systems with refusals the requirements for optimisation of the system are as follows:

$$
\begin{gathered}
P_{t}=I_{t}-C_{z(s), t}^{a t t} \rightarrow \max \\
P_{\text {nesan }, t}^{\text {att }}=P_{0}^{\text {att }} \cdot p_{\text {att }} \cdot \lambda \cdot t \rightarrow \min
\end{gathered}
$$

(in cases where the operating system optimization can be solved with one of the optimization tasks (see formulae 12 and 13)):

$$
I_{t} \rightarrow \max
$$

i.e., the maximisation of income derived from AS operation over the time frame $t$ or

$$
C_{z(s), t}^{a t t} \rightarrow \min
$$

i.e., minimisation of expenses associated with system functioning in the time frame $t$. 
Table 2. Heating system average fuel consumption

\begin{tabular}{|c|c|c|c|c|c|}
\hline \multicolumn{6}{|c|}{ Working Day } \\
\hline Time & Temperature & $\begin{array}{c}\text { Used Heating Power } \\
(\mathrm{kW} / \text { hour })\end{array}$ & Used Fuel (kg) & $\begin{array}{c}\text { Active Heating } \\
\text { Boiler }\end{array}$ & $\begin{array}{c}\text { System } \\
\text { Running Costs }\end{array}$ \\
\hline $00-02$ & -8 & 175 & 90 & 3 & 16.83 \\
\hline $02-04$ & -10 & 310 & 180 & 6 & 33.66 \\
\hline $04-06$ & -12 & 280 & 150 & 5 & 28.05 \\
\hline $06-08$ & -10 & 120 & 60 & 2 & 11.22 \\
\hline $08-10$ & -7 & 180 & 90 & 3 & 16.83 \\
\hline $10-12$ & -4 & 120 & 60 & 2 & 11.22 \\
\hline $12-14$ & -4 & 110 & 60 & 2 & 11.22 \\
\hline $14-16$ & -6 & 160 & 90 & 3 & 16.83 \\
\hline $16-18$ & -6 & 210 & 120 & 4 & 22.44 \\
\hline $18-20$ & -8 & 310 & 180 & 6 & 33.66 \\
\hline $20-22$ & -8 & 300 & 150 & 5 & 28.05 \\
\hline $22-00$ & -10 & 220 & 120 & 4 & 22.44 \\
\hline \multicolumn{6}{|c|}{ Holiday } \\
\hline Time & Temperature & $\begin{array}{c}\text { Used Heating Power } \\
\text { (kW/hour) }\end{array}$ & Used Fuel (kg) & $\begin{array}{c}\text { Active Heating } \\
\text { Boiler }\end{array}$ & $\begin{array}{c}\text { System } \\
\text { Running Costs }\end{array}$ \\
\hline $00-02$ & -10 & 280 & 150 & 5 & 28.05 \\
\hline 02-04 & -12 & 280 & 150 & 5 & 28.05 \\
\hline 04-06 & -14 & 300 & 150 & 5 & 28.05 \\
\hline $06-08$ & -12 & 220 & 120 & 4 & 22.44 \\
\hline 08-10 & -12 & 220 & 120 & 4 & 22.44 \\
\hline $10-12$ & -8 & 320 & 180 & 6 & 33.66 \\
\hline $12-14$ & -7 & 300 & 150 & 5 & 28.05 \\
\hline 14-16 & -6 & 280 & 150 & 5 & 28.05 \\
\hline $16-18$ & -8 & 300 & 150 & 5 & 28.05 \\
\hline $18-20$ & -10 & 320 & 180 & 6 & 33.66 \\
\hline $20-22$ & -10 & 300 & 150 & 5 & 28.05 \\
\hline $22-00$ & -11 & 300 & 150 & 5 & 28.05 \\
\hline
\end{tabular}

\section{METHOD PRACTICAL APPROBATION}

\section{Objective of the Experiment}

1. To verify the existence of an economic parameter change to the servicing system described in the article, depending on the operational scenarios of the model.

2. To check the efficiency of the management scenarios for the modelling module as compared to the operating scenario of the defined heating system (system operation scenarios are changed automatically when determining the most efficient modelling result).

\section{Experiment Entry Data}

The experiment was based on a single heating system with a total power of $360 \mathrm{~kW}$, which provides 10 homes and 1 commercial facility with heat energy. The heating system consists of 6 servicing devices with a nominal capacity of $60 \mathrm{~kW}$ (Viessman Vitogas 100) and 11 sending sources (potential customers in queue). The technical characteristics of the heating system were not changed during experiments, the daily system was operated using the industrially defined operating structure and all boilers operate simultaneously by controlling the required capacity through the applicable FuzzyLogic control module described in other papers (Jurenoks, 2015; Jurenoks and Novickis, 2015). As a result, it can be considered that the resources consumed to ensure the functioning of the system can be considered as constant value at an external air temperature during one period (Table 2).

\section{Summary of Results of the Experiment}

The three heating system operation scenarios have been isolated during experiments in the Table 2: the date (time 10:00 - 16:00), night time (24:00 - 5:00), holiday (time 5:00 - 10:00; 16:00 - 24: 00; all holidays). During each period, the number of service system requests and capacity for servicing equipment are different. The result is that the use of the modelling method would result in an increase in the economic efficiency of the system at day and night mode (Figure 3). 


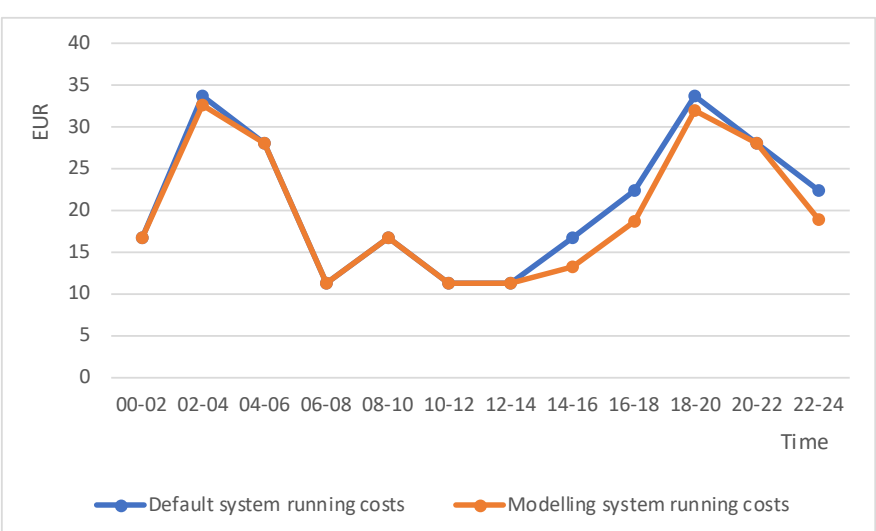

Figure 3. Heating system fuel consumption using modelling result control scenario in working day

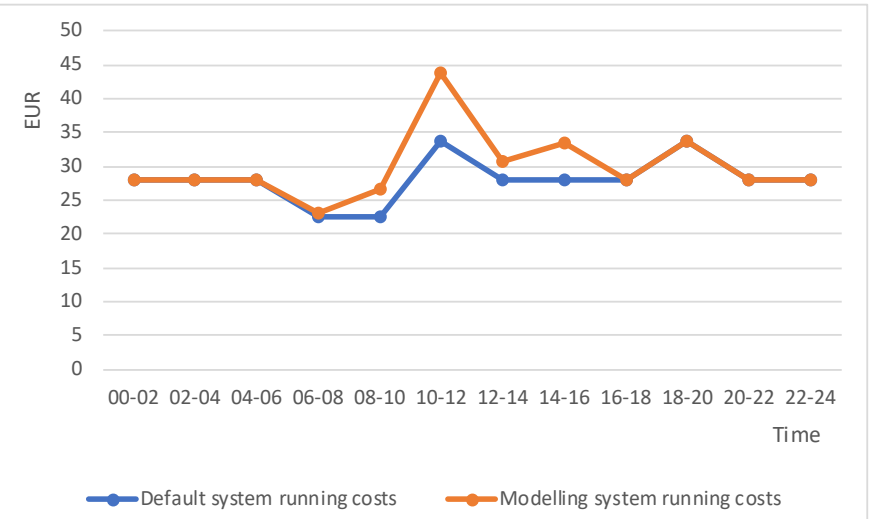

Figure 4. Heating system fuel consumption using modelling result control scenario in holiday's

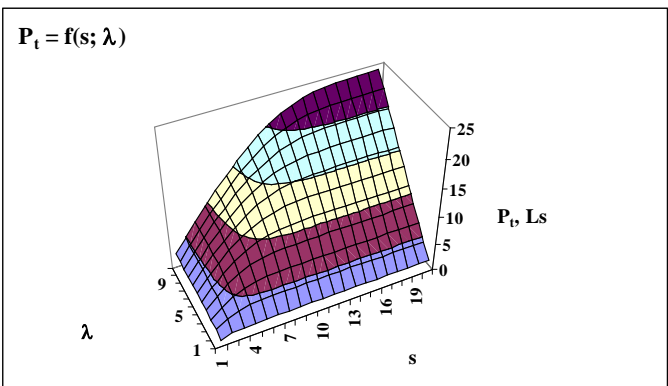

Figure 5. The diagram of function $P_{t}=f(s,(s, \lambda))$ of the modelled system

The "holiday" mode could not predict the number of planned requests and as a result the time required to model efficiency was greater than the duration of the required system response (Figure 4).

It can be concluded that:

1. Through an economic efficiency optimisation technique, the number of small requests can lead to an increase in the overall economic efficiency of the system by reducing the number of service devices and increasing the length of the request.

2. In systems with variable requests, the economic efficiency of Random $(\lambda)$ system can be ensured through the knowledge base of a definition in terms of modelling techniques, as the time required for the modelling process and the effective mechanical engineering is greater than the response time.

When using the graphical model obtained during an experiment that describes the parameter $P_{t}$ (the profit that is gained from the period of operation of the servicing system in the time frame $t$ ) change of dependence on parameter $s$ and the change of $(s, \lambda)$ (Figure 5), it is indicated that the existence of the economic parameter change of the service system $\left(P_{t}\right)$ depending on the technical parameters of the model of parameter $s$, the $(s, \lambda)$ changes.

During the experiments, using a change in the operation scenarios of the heating system, in most cases, an increase in the economic efficiency of the system during the last time period is shown (Table 3). 
Table 3. In working day used Heating system optimization results

\begin{tabular}{cccccc}
\hline Time & Temperature & $\begin{array}{c}\text { Used Heating Power } \\
(\mathbf{k W} / \mathbf{h o u r})\end{array}$ & Used Fuel (kg) & $\begin{array}{c}\text { Active Heating } \\
\text { Boiler }\end{array}$ & $\begin{array}{c}\text { System } \\
\text { Running Costs }\end{array}$ \\
\hline $00-02$ & -8 & 175 & 90 & 3 & 16.83 \\
\hline $02-04$ & -10 & 310 & 176 & 5 & $\mathbf{A} 2.6$ \\
\hline $04-06$ & -12 & 280 & 150 & 3 & 28.05 \\
\hline $06-08$ & -10 & 120 & 60 & 2 & 11.22 \\
\hline $08-10$ & -7 & 180 & 90 & 3 & 16.83 \\
\hline $10-12$ & -4 & 120 & 60 & 2 & 11.22 \\
\hline $12-14$ & -4 & 110 & 60 & 2 & 11.22 \\
\hline $14-16$ & -6 & 160 & 72 & 13.32 \\
\hline $16-18$ & -6 & 210 & 101 & 3 & $\mathbf{A}$ \\
\hline $18-20$ & -8 & 310 & 173 & 5 & $\mathbf{A} .755$ \\
\hline $20-22$ & -8 & 300 & 150 & 5 & 28.075 \\
\hline $22-00$ & -10 & 220 & 102 & 3 & $\mathbf{A}$ \\
\hline
\end{tabular}

It can be deduced from the above that the economic efficiency modelling technique described in the article works, but in order to increase the efficiency, the knowledge base of the above dynamic system should be used as a basis for determining the dependence of system operating algorithms during the period stipulated in the request trend. These will allow decreasing the time of system response to change in request.

\section{CONCLUSION}

Economic modelling makes it possible to obtain a large number of solutions which should be analysed and only as a result of the analysis may lead to an economic decision. The result to be obtained in the process of economic modelling may be dynamically subject to changes in the system input parameters by enabling real time to see the real object behaviour in the range of changes to the parameters in question and take corrective action. Economic modelling can be compared to the creation of a "road map". It shows the main roads and other information characterising the system's internal and external environment. When using automated service systems, the automated service systems will be able to choose the correct path to be used in the defined situation. The modelling method explored in this article will be used to improve the knowledge base of the management system which will enable the dynamic incorporation or rectification of events in the knowledge base during the operation of the system, using the information obtained during modelling and an expert opinion.

The analysis of methodological modelling results described in the article once again prove a specialist's (manager's) role in decision-making in the context of the functioning of complex technical economic systems. The adoption of a decision on an increase in the number of servicing devices will only take into account the value of other parameters of the model (system) within the range of parameter changes within the range of parameters.

In future studies, the author plans to integrate the developed economic efficiency modelling technique into the FuzzyLogic systems which will ensure automatic decision-making and management of economically efficient processes.

\section{ACKNOWLEDGMENT}

This work is partly funded by Latvian Council of Science project Z12.0342 "Development of Models and Methods Based on Distributed Artificial Intelligence, Knowledge Management and Advanced Web Technologies for Applied Intelligent Software".

\section{REFERENCES}

Badea, C.A. and Andrei, H. (2016). Optimization of Energy Consumption of a Wastewater Treatment Plant by Using Technological Forecasts and Green Energy. In 2016 IEEE 16th International Conference on Environment and Electrical Engineering (EEEIC). IEEE, pp. 1-5. https://doi.org/10.1109/EEEIC.2016.7555734.

Broomhead, T., Manzie, C., Hield, P., Shekhar, R., Brear, M. (2017). Economic Model Predictive Control and Applications for Diesel Generators. IEEE Transactions on Control Systems Technology, 25(2), pp. 388-400. https://doi.org/10.1109/TCST.2016.2574758

Jansons, V. and Jurēnoks, V. (2005). Economics modelling book. Riga: RTU Izdevniecība. 
Jansons, V. and Jurēnoks, V. (2006). Ekonomiskà modelèsana piemèros. Apkalpošanas sistèmas ar atteikumiem. Rīga: RTU Izdevniecība.

Jurenoks, A. (2015). Method for Node Lifetime Assessment in Wireless Sensor Network with Dynamic Coordinator. In 2015 IEEE 3rd Workshop on Advances in Information, Electronic and Electrical Engineering (AIEEE). IEEE, pp. 1-5. https:// doi.org/10.1109/AIEEE.2015.7367302

Jurenoks, A. and Jokić, D. (2017). Sensor Network Information Flow Control Method with Static Coordinator within Internet of Things in Smart House Environment. Procedia Computer Science, 104, pp. 385-392. https://doi.org/10.1016/j.procs.2017.01.150

Jurenoks, A., Novickis, L. (2015). Wireless Sensor Network Live Circle Simulation Tools to Balance Energy Consumption in the Network Nodes. In Proceedings of 29th European Simulation and Modelling Conference, Leicester, United Kingdom, 26-28 October. ISBN 978-9077381-908, pp. 245-249.

Jurenoks, V. and Jansons, V. (2008). The Use of Specialized Programs for Modelling and Analysis of Behaviour of Economic Systems. In RTU International Scientific conference, Riga, RTU, 16 Edition, pp.72 -80.

Lapin, L.L. (1993). Statistics for Modern Business Decisions. The Dryden press. Harcourt Brace College Publishers.

Li, C., Wei, F., Lu, S. and Zeng, J. (2016). Dynamic Energy Portfolio Optimization Model for Electricity System and Heating System. In 2016 IEEE International Conference on Industrial Engineering and Engineering Management (IEEM). IEEE, pp. 1677-1682. https://doi.org/10.1109/IEEM.2016.7798163

Хэмди, А. and Таха, Х. (2001). Введение в исследование операций. 912 с. Пер. с англ. М. Издательский дом "Вильямс".

Экономико - математические методы и прикладные модели. (1999). Под ред. В. В. Федосеева. 391 с. М. ЮНИТИ. 